\title{
La pedagogía crítica como herramienta idónea para desarrollar una posición crítica y reflexiva antes las NTICs en Latinoamérica
}

Juan Gómez Torres ${ }^{57}$

\section{Introducción}

Este ensayo aborda, de manera preliminar, una serie de aspectos vinculados con la pedagogía crítica como herramienta pedagógica idónea para desarrollar una posición crítica y reflexiva ante las Nuevas Tecnologías de la Información y la Comunicación (en adelante NTICs) en Latinoamérica, el mismo forma parte de un proyecto de investigación mucho más amplio. La tesis principal que sostenemos en este trabajo es que las NTICs responden al contexto socio histórico y a los intereses de quienes las crearon, administran, y toman las decisiones de su uso. Es decir,

Licenciado en Administración Educativa, egresado de la Licenciatura en Teología, bachiller en Filosofia, bachiller en Enseñanza de la Filosofía y hachiller en Enseñanza de la Religión. Actualmente labora como docente e investigador en la División de Educologia (Universidad Nacional, Costa Rica) y es egresado de la Maestría de Estudios Latinoamericanos con énfasis en Cultura y Desarrollo, U.N.A. 
ellas por sí solas no son ni buenas ni malas, dependen de los valores y contenidos ideológicos que expresan. Por tanto, al implicar razones éticas y políticas las NTICs se deben abordar de la forma crítica, reflexiva y no como simples objetos mesiánicos.

La reflexión sobre las NTICs debe abarcar su uso y fines; determinando si esos usos son mediaciones para alcanzar un fin ético y político, o si son un fin en sí mismo, si instrumentalizan al sujeto o, por el contrario, le posibilitan su emancipación. El mediador pedagógico y el educando, por el carácter crítico, reflexivo y político de la educación, deben realizar una profunda reflexión sobre la procedencia, fines e intenciones de quienes producen las NTICs y sus posibles efectos en los educandos. Por tanto, dependiendo del uso que se les dé a las NTICs pueden ser medios educativos que formen parten de una plataforma política, cultural, social, humanista, ecológica, ética, inclusiva y acciones claras que promuevan la calidad de vida en todos los seres humanos.

El presente ensayo pretende alejarse del sentido determinista, instrumentalizado, irracional y mágico que se le ha dado a las tecnologías en el modelo de desarrollo mercadocéntrico, propio de la globalización neoliberal, al punto de considerar que las NTICs son causantes de un nuevo período histórico de la sociedad humana ${ }^{58}$; a saber, la denominada Sociedad de la Información (SI). Consideramos necesario desmitificar esa utopía antiutópica ${ }^{59}$, debido a la innegable influencia de las NTICs en el período histórico que vivimos ${ }^{60}$. El ignorar su relevancia en el plano de la

\footnotetext{
is Presenta dicho período al neoliberalismo como el fin de una historia (Fukyama) o el fin de las ideologías (Toffler).

54 Parafraseando a Hinkelammert (1990), quien considera que el neoliberalismo se presenta como la última utopía posible, como el fin de la historia anunciado desde Hegel. (x) Período que sigue siendo modernista, aunque con un neo radicalismo de sus principios fundantes; a saber, el racionalismo, el cientificismo, capitalismo-economicismo, fragmentación, especialización, mercantilismo-capitalismo...
} 
sociedad actual sería tan erróneo e ingenuo como asignarles ese papel determinista.

Para establecer vínculos inclusivos entre las comunidades, fortalecer la participación ciudadana y reducir las diferencias sociales y culturales, disímil de lo que predica la globalización neoliberal, se necesitan políticas públicas propias de un Estado solidario. En ese marco, se propone a la Pedagogía Crítica como elemento esencial de una política educativa que puede concienciar al sujeto, emanciparlo, alfabetizarlo críticamente o formarlo integralmente para que desarrolle una posición crítica y reflexiva ante la vida, y por ende, anta las NTICs y para que pueda transformar aquellas realidades que oprimen, deprimen o suprimen como sujeto $^{61}$.

\section{Las NTICs: determinismo tecnológico o instrumentos transformados por la sociedad}

Ha existido una larga discusión sobre el carácter determinista de las TCIs y las NTICs. La modernidad occidental las ha presentado como un elemento indispensable para el desarrollo de económico, social y culturai, sin el cual no se alcanzaría el progreso ("desarrollo"), al punto de creer que el sólo hecho de poseerlas es un sinónimo de ascenso, de avanzada hacia el camino del "bienestar". De tal modo, que sin ellas no hay utopía civilizadora, e incluso algunos siguen sosteniendo que ellas determinan al todo social.

Desde el punto de vista de este ensayo, las tecnologías son solo una herramienta al servicio de la sociedad humana, las que pueden ser utilizadas por dicha sociedad como un medio, entre otros, para construir un modelo de

Sujeto creativo y creador de la historia, de su historia y participe de la histuria de su 
desarrollo humanista; por tanto, según sea el contexto socio histórico en el que se crean y al que responden las NTICs, podrían privilegiar el mal desarrollo ${ }^{62}$, como lo hace actualmente, $o$, por el contrario, también podrían privilegiar el buen desarrollo ${ }^{63}$.

Para que el uso de las tecnologías esté al servicio del buen desarrollo, es central el papel de la educación, por ser un área de la sociedad humana que puede integrar otras áreas con la misma importancia, como la política, la ética, la economía, la social, la cultural y la ecológica. Ese carácter integrador de la educación humana manifiesta la posibilidad de autotransformación del ser humano y de la sociedad misma; un carácter perenne de perfeccionamiento propio del sujeto histórico inacabado, el que requiere de un proceso de formación integral, meta de la pedagogía crítica.

\section{Las NTICs y la educación en América Latina}

El uso educativo de las NTICs en América Latina ha estado desvinculado de un proyecto alternativo de sociedad, de desarrollo y de cultura; ni siquiera ha dado lugar para usos diferentes de las mismas, usos que puedan humanizar sus propósitos materialistas, y cuando se ha hecho, ha surgido de iniciativas alternativas, no oficiales, y, hasta contrahegemónicas en el sentido gramsciano. Esos usos alternativos y diferentes han surgido de actores emergentes de la sociedad civil, o como describe Castells, del ser humano responsable, conciente de sus deberes y derechos e informado de la realidad que le circunda ${ }^{64}$. Eso no significa

\footnotetext{
$\overline{62}$ Los conceptos de Mal desarrollo y Buen desarrollo son abordados por Carmen (2004), en su obra Desarrollo Autónomo.

6) Siguiendo a Nerfín (1975, citado por Carmen, 2004, p. 43), se entiende por buen desarrollo aquel que contenga al menos cinco elementos básicos; a saber, orientado desde las necesidades, surgido de forma endógena, sustentable a partir de su autosuficiencia y de su salubridad en términos ecológicos y finalmente ha de estar basado en transformaciones estructurales.

64 Eso implica un proceso educativo ya sea formal e informal.
} 
menospreciar la necesidad de la institucionalidad, la democracia participativa, una política pública eficaz, lo que es posible solo con "gobiernos responsables y verdaderamente democráticos" (Castells: 2003, p. 353).

Una actitud crítica y alternativa ante las NTICs evita su rechazo categórico a su recepción pasiva. Las tecnologías en mención, en muchos casos, han facilitado y potenciando el aprendizaje humano, incrementando la eficiencia de los procesos de enseñanza, pero es cuestionable su eficacia si antes no se sabe para qué aprender lo que se aprende, para qué sirve, cuáles son sus efectos, beneficios y perjuicios, y cuál es el papel de las NTICs en ese contexto. Entonces, si se desconoce esa realidad podríamos plantarnos las siguientes preguntas, entre otras posibles: iqué tienen de nuevas?, ¿qué tipo de aprendizaje potencia?, ¿cuál es su papel innovador?

Por ello, el análisis de las relaciones entre educación y las nuevas tecnologías exige una actitud reflexiva "a priori", pues las buenas intenciones, los interese y las necesidades de las instituciones educativas, por más contextuadas que estén, no son suficientes por sí solas en este tema. Se debe reflexionar sobre los discursos pedagógicos, sobre su impronta en el tema de las NTICs, sobre su capacidad de incorporarlas críticamente, sobre su creatividad para adaptarlas y recrearlas, entre otras especulaciones válidas al respecto. Pero para entender los discursos pedagógicos es necesario comprender la cultura escolar ${ }^{65}$ como lugar de relaciones políticas, sociales y emocionales; esto es, espacio de prácticas discursivas y culturales, de acciones políticas

\footnotetext{
65 Para Ángel Pérez (2000), la cultura escolar es "un espacio ecológico de cruce de culturas, cuya responsabilidad específica es la mediación reflexiva de aquellos influjos plurales que las diferentes culturas ejercen de forma permanente sobre las nuevas generaciones, para facilitar su desartollo educativo" (p. 76). Como lo indica el autor, dicho cruce es fluido y complejo, allí convergen cultura hegemónico-social, acadénica, crítica, curriculat, institucional y experimental (ídem, p. 17).
} 
hegemónicas y contra hegemónicas, de actividades curriculares y extracurriculares, de encuentros y desencuentros identitarios.

Es necesario realizar un análisis profundo sobre las NTICs y su desarrollo en las culturas escolares, pues además de su probabilidad de potenciar el aprendizaje y motivar a los estudiantes, las nuevas tecnologías también tienen sus efectos en la formación política de los ciudadanos, en la configuración y transmisión de ideas y valores ideológicos, en el desarrollo de actitudes hacia la interrelación y convivencia con los demás seres humanos. Eso muestra que se contenido no es neutral como pretenden presentarlo algunos deterministas tecnológicos.

Más que nunca es necesaria una actitud crítica ante las NTICs, pues en América Latina los sistemas educativos han sido receptores pasivos de esa masiva incorporación de medios, mostrándose inhabilitados en los procesos de enseñanza-aprendizaje, pues no es extraño su ausencia total en muchos rincones del continente. En el caso de las instituciones que las poseen y las han incorporado, las nuevas tecnologías se han ejecutado como una mera intrusión, como algo que necesariamente ha de utilizarse, pero sin saber muy bien por qué y cómo; sin conocer los efectos de su uso en el aprendizaje, en el currículo y en la organización de la propia institución (Gros, 2000).

Esta realidad de precarización, de ausencia de estos medios, o de hoyo negro en el avance tecnológico me lleva a preguntar sobre su efecto político económico en América Latina. 


\section{Las NTICs: ¿instrumentos democratizadores o medios de exclusión económico, social y cultural para Améri- ca Latina?}

Como se ha insinuado, la "respuesta" educativa de América Latina para enfrentar esa situación ante las nuevas tecnologías ha si precaria, no se ha dado, o se ha dado parcialmente, pues su énfasis ha estado en la cualificación y ha sido posible, sobre todo, en el sector de la educación privada, que deja por fuera a grandes sectores de la sociedad, pues la educación pública (la que ya de por sí es bastante excluyente) no tiene posibilidades de acceso amplio a esas tecnologías en el marco del modelo de desarrollo imperante, abiertamente inclinado hacia la desregulación y desfinanciación del Estado.

Esa tendencia desreguladora de las funciones sociales y del equilibrio del Estado, parece reducir sus funciones a la vigilancia y cumplimiento de los contratos, sobre todo los de índole económico, es decir, la desregulación es entendida como la adaptación de las leyes según los intereses de la inversión privada, privatización de los servicios públicos y los recortes en el gasto público y social, afectando el bienestar social. Esta situación imposibilita aún más la democratización del acceso a dichas tecnologías.

Para Rivero (1999), la globalización neoliberal tiene un efecto empobrecedor sobre la sociedad latinoamericana. Sostiene que la educación es prioritaria para transformar ese modelo rapaz y considera que el analfabetismo (incluido el nuevo analfabetismo de las NTICs), las pocas oportunidades de estudio y la exclusión del acceso a las NTICs, entre otras, son las principales expresiones educativas de la pobreza. Sigue creyendo en la educación como medio de movilidad social o como un instrumento para salir de la pobreza en la que se encuentra actualmente en América Latina. 
El problema de la exclusión tecnológica es tan grande que, según Patalano (2004, citada por Córdoba, 2005), América Latina no forma parte de la Sociedad de la Información, "aunque una parte de su población participe como productora y consumidora de la sociedad global de la información, a la vez que vive con amplios y mayoritarios sectores marginados, como consecuencia del desigual desarrollo histórico" (p. 4). Centroamérica es un buen ejemplo de tal realidad, pues sus prioridades están en resolver las necesidades básicas y elementales, no resueltas con las guerras del pasado (ni con la falsa paz del presente) pues las causas estructurales que originaron la guerra no solo subsisten sino que se han agravado. Dado el nivel de subdesarrollo o mal desarrollo de la región, a pesar de las promesas del modelo desarrollista de un bienestar para todos, en la realidad se ha visto incrementada la desigualdad y la pobreza externa.

En el modelo neoliberal, las NTICs son un instrumento indispensable para producir riquezas, para aumentar ganancias y para desarrollar buenos negocios (por esa razón se concentra su uso en unos pocos). Son aliadas propagadoras de un nuevo factor de desigualdad social y de mayor separación y distancia cultural entre aquellos sectores de la población que tienen acceso a las mismas y los que no. Como prueba de ello, existe una inmensa cantidad de estudios que revelan el alto grado de inequidad que producen (por ejemplo Castells, 2003, con el caso de Internet).

Otro ejemplo, de esa inequidad en la tenencia, uso y producción de las NTICs, según Area (1998), p. 4), lo representa la nueva organización de dichas tecnologías, pues ellas segregan la oferta audiovisual tradicional, afectando la forma de socialización y de cultura. Es decir, por un lado están los medios tradicionales como la radio, la TV, la telefonía fija, y por el otro los digitales como Internet, la TV por cable y la telefonía móvil; dualidad que implica un nuevo 
foco de exclusión para quienes solo tienen acceso a las tecnologías tradicionales, quedando excluidos de una oferta cultural más variada, más personalizada y posiblemente de mayor calidad.

Por ello, el mismo Manuel Area (1998) afirma que "la desigualdad tecnológica agrandará todavía más las distancias culturales y económicas entre unos y otros grupos sociales. Las Nuevas Tecnologías de la Información y Comunicación pueden separar más que unir. Estrechan la comunicación entre quienes la utilizan, pero excluyen a quienes no" (p. 5). Esos excluidos son sin lugar a dudas los nuevos analfabetos, los que no participan de una parte importante de la información que no está impresa.

De esta visión panorámica sobre el uso desigual de las NTICs en Latinoamérica, se infiere la necesidad de plantear alternativas de carácter político y éticas que lleven a estrechar esa brecha y subsanar las desigualdades, las que provocan desequilibrio y fragmentación social. Ello es urgente, sobre todo, ante los discursos ideológicos de fin de siglo XX que sostenían el fin de la historia, antiutopía que he mencionado y que ha estado presente en los deterministas tecnológicos, en los pesimistas culturales y en quienes luchan por conservar su estatus quo ( Giroux, 2003, p. 25-28).

Para democratizar las NTICs y evitar esos desequilibrios sociales y culturales, agravados por el uso desigual, el Estado debe intervenir a través de políticas sociales, culturales y educativas (situación respaldada por gran cantidad de teóricos especializados en este campo, por ejemplo: Castells (2003), Yúdice (2001) y (1999), y Álvarez (1999), que nivelen las desigualdades tecnológicas de los grupos sociales más desfavorecidos y que aprovechen sus beneficios para el bienestar de toda la población, especialmente de los que más lo necesitan. 


\section{La Pedagogía Crítica como herramienta idónea para de- sarrollar una actitud crítica y propositiva ante las NTICs en América Latina}

Es necesaria una política educativa, que puede surgir desde abajo, desde la base popular, de los grupos de presión o de distintos actores que abogan por un nuevo y más humano desarrollo, quienes han de participar en la construcción del nuevo currículum necesario según la realidad de cada comunidad. Pero también puede surgir desde arriba, por la presión ejercida por los grupos mencionados, por una toma democrática del poder político por parte grupos políticos concientes de la inviabilidad "sine qua non" del modelo de desarrollo vigente, dadas sus acciones materialistas, excluyentes y de sobreexplotación del planeta. Ese desde "arriba" solo es posible con la participación de los de abajo.

Esa nueva política educativa debe contener o desarrollar una actitud crítico política ante las NTICs, para lo cual necesita integrarlas como un contenido curricular y como un instrumento didáctico, para hacer un uso pedagógico de las mismas. Al respecto Romero Morante afirma que "en efecto, ningún medio es educativo hasta que no se "construye" pedagógicamente" (citado por Tedesco, 1997). Giroux, por su parte, considera que la pedagogía más que una herramienta técnica o un manifiesto de "buenas" intenciones, debe ser considerada como una práctica política y ética encausada hacia el desarrollo de un sentido de sujeto, de identidad, de ciudadano y de vida pública, dentro de una perspectiva crítica de lo cultural y global (2003, pp. 131-132).

Para construir ese camino crítico y propositivo hacia otro desarrollo, el carácter educativo del ser humano es central, pues con él se puede lograr su emancipación utilizando la pedagogía adecuada para ello. Según Freire, esa tarea la 
puede lograr la Pedagogía Crítica, pues ella consigue que nos asumamos como sujetos históricos, inacabados y solidarios; de este modo, la Pedagogía Crítica se plantea como una metodología capaz de "concientizar" ${ }^{66 "}$ al sujeto o dicho de otra forma, se presenta como un material para que el oprimido construya, por sí mismo, los medios y los procesos para su liberación.

De este planteamiento surge una pregunta ¿cómo puede alcanzar la Pedagogía Crítica ese objetivo emancipador con unas herramientas que han sido utilizadas y creadas para las necesidades y fines del modelo de desarrollo cuestionado por este ensayo? En relación a este tópico, Giroux (1997) manifiesta que para la Pedagogía Crítica, profesores y estudiantes apoyan, resisten o adoptan los lenguajes, las ideologías, los procesos sociales y los mitos que los sitúan dentro de las actuales relaciones de poder y dependencia. Esta pedagogía cuestiona la forma en que ese proceso se desarrolla y, a su vez, examina cómo se producen y transforman los procesos culturales a través de los discursos de la producción, del análisis de textos y de las culturas vivas (p. 153 . 157). Para él estudiar pedagogía no debería confundirse nunca con el hecho de que otros te digan lo que hay que hacer, por tanto, implica una actitud crítica y creativa ante las NTICs.

El carácter mediador de esa pedagogía posibilita las condiciones para que los oprimidos construyan su propio proceso emancipador (Freire, 2003, p. 42), llevando al estudiante a ser sujeto de su propia formación (ídem., p. 43) de modo que sea capaz de transformar su realidad y de buscar sus propios caminos de lucha (ídem., p. 60). De esta

\footnotetext{
66 En Freire, la concientización es una suma entre la teoría y la acción o entre el pensamiento crítico y la práctica cotidiana; donde ambas conforman una unidad indisoluble y necesaria para la transformación de la realidad por parte de los sujetos; el sujeto construye y propone alternativas para ponerlas en marcha y de ese modo crear las condi. ciones de emancipación, propias de un mundo más justo y solidario.
} 
manera, parafraseando a Freire, el sujeto tendrá la palabra, la pedagogía debe devolverle la palabra, debe posibilitar su autoliberación, desde donde podrá realizar las acciones políticas y éticas necesarias para transformar su entorno, construyendo un mundo más equitativo y justo, en el que quepamos todos (como diría el Subcomandante Marcos).

Para llevar a cabo esa labor reflexiva en el campo educarivo, la Pedagogía Crítica posibilita que el estudiante construya acciones politicas, estéticas y éticas (Freire, 2003, p. 42), que mejoran su nivel de interpretación, acción, creacién y reconstrucción de la realidad, de los modelos político-ideológicos, y del currículum. En este contexto, se pueden utilizar las NTICs ${ }^{67}$ (cuando se tengan) al servicio de la emancipación del oprimido y para construir un nuevo modelo de desarrollo humanista, equilibrado e integral.

La Pedagogía crítica ve a la enseñanza como un aprendizaje dialéctico, dialogal y social: "quien enseña aprende al enseñar y quien aprende, enseña al aprender" (Freire, 2003 , p. 40), por lo que su posición es horizontal, popular y democratizante. Freire sostiene que "la educación verdadera es praxis, reflexión y acción del hombre sobre el mundo para transformarlo" $(1980$, p. 7$)$ y por tanto, el fundamento de su praxis está "en la convicción de que el hombre fue creado para comunicarse con los otros hombres" (p. 8). Es decir, la educación es dialogal, es una práctica de libertad, de amor, un proceso problematizador, participativo, democrático y un acto solidario de transformación de la realidad (p. 85).

Para McLaren la enseñanza es necesaria para la formación humana integral; el fortalecimiento personal y social debe ser previo a lo epistemológico y al desarrollo de

\footnotetext{
67 Los que, siguiendo la Pedagogía Crítica, deben ser probiematizados por los docentes y los educando en un diálogo cultural emancipador.
} 
habilidades técnicas o sociales y por lo tanto es una tarea fundamental de la Pedagogía Crítica. Plantea la pedagogía como una práctica de lo correcto, fundamentada en "una política de la ética, la diferencia y la democracia" (1997, p. 43). Así vista, la pedagogía crítica promueve un nuevo tipo de sociedad y de ser humano, uno más integral, crítico, reflexivo, problematizador, transformador, creativo, ecológico...Para ello propone la (re)construcción de un nuevo currículo, un currículo contextualizado, donde el educando ha de ser sujeto de su propia formación, de modo que sea capaz de transformar su realidad y de buscar sus propios caminos de lucha (Freire, 2003, p. 60). Se pretende dar primacía a la formación integral sobre la cualificación para el mercado.

En el currículo vigente en América Latina se privilegia lo técnico, lo pragmático, y lo epistemológico, sobre lo afectivo, lo ético, lo histórico, lo cualitativo, lo político, lo social y lo cultural; esas acciones inhiben el espíritu crítico. Por eso Giroux denuncia que la escuela abandonó su dimensión de cuestionamiento político social; esto es, ya no estudia aquellos temas relacionados con las estructuras de poder propias de su entorno, ni temas acerca de la justicia social, dejando de lado estos elementos constituyentes de la relación entre práctica cultural y política democrática (p. 20-21).

Por su espíritu crítico, en suma, este modelo pedagógico lleva a cuestionar el discurso determinista de las tecnologías, pues el sujeto alfabetizado críticamente, formado integralmente, podría tomar una actitud reflexiva y problematizadora ante las NTICs, las podrá ver como instrumentos no inofensivos ni neutrales que pueden servir tanto para alfabetizar críticamente y para ser usados en aras del bien común, mejorar la calidad de vida o construir un modelo de desarrollo humanista. 
Dicho de otra forma, como lo sostiene Area, se deben desarrollar "procesos formativos dirigidos a que la ciudadanía: aprenda a aprender, sepa enfrentarse a la información (buscar, seleccionar, elaborar y difundir), se cualifique laboralmente para el uso de las NNTT ${ }^{68}$, tome conciencia de las implicaciones económicas, ideológicas, políticas y culturales de la tecnología en nuestra sociedad" (1998, p. 6).

\section{La Pedagogía Crítica, Cultura Popular y Cultura Política}

El modelo desarrollista ha excluido a la clase popular del proceso de toma de decisiones, del proceso de producción y reproducción de las NTICs y del derecho de potenciar alternativas políticas en las que se incluya a las tecnologías como medios democratizadores y democratizantes. Como se ha apuntado, a la clase popular se le ha negado ese derecho fundamental a través de una educación y una cultura de sometimiento y subordinación a las reglas del mercado.

Eso no significa que todo está acabado, que no hay más que la "democracia" neoliberal, que no hay más utopías posibles; pues por la condición espiritual del ser humano, son posibles un sinfín de alternativas ${ }^{69}$, entre ellas, la ofrecida o facilitada por la Pedagogía Crítica Latinoamericana ${ }^{70}$ como una expresión de ese espíritu humano insurrecto ante acciones que pretenden aplacarlo. Ese espíritu

\footnotetext{
o8 Siglas que el autor utiliza para referirse a las Nuevas Tecnologías, lo que para noso. tros son las NTICs.

(6) Las mismas han ido surgiendo sobre todo en América del Sur, por sus condiciones extremas de pobreza, exclusión, miseria, enajenación... dando como resultado un despertar del espíritu humano, una búsqueda de caminos para salir de una crisis inducida por el mercado mundial y las hegemonías locales, esas alternativas han surgido de la base social (del pueblo), de los sectores más afectados y discriminados. Aún están lejos de alcanar un nuevo modelo de desarrollo, pero nunca ha sido tan clara su necesidad y su clamor popular.

70 Esta opción ha llegado hasta países ricos como USA y Canadá, los que, como otros países ricos, tienen clases sociales en extrema pobreza, en situaciones de explotacién deshumana y con altos niveles de enajenación.
} 
indomable manifiesta el carácter político y ético del ser humano, inmerso en un contexto histórico, social y en donde desarrolla su perfectibilidad.

Por esa razón, Giroux manifiesta la necesidad de la "Revitalización de la Cultura de la Política", aunque crea que la Política la hayan denigrado como parte de un proceso deslegitimador, se le haya reducido a una elección entre el estatus quo y algo peor, es decir, se procura su agotamiento $(2003$, p. 12$)$, a tal extremo que, para el autor, la única forma política o de participación que tienten los "ciudadanos" es el consumismo, en contraposición a las formas sustantivas de ciudadanía.

Giroux asevera que la participación posible en el modelo desarrollista o en la "democracia" neoliberal se produce como consumidores en vez de ciudadanos, y en centros comerciales en lugar de comunidades, dando como resultado una fragmentación o atomización de lo comunitario. Así la desmoralización se implanta como forma de vida: al no contar con ningún poder a nivel social, grandes masas de desechados deambulan por las ciudades latinoamericanas, desesperanzados, excluidos y expulsados.

Esas prácticas consumistas o nuevas formas de participación "democráticas" son inoperantes en un marco de transformación social, por ello, para que la democracia sirva, es necesario el vínculo popular o comunitario, que las personas vivan en relación con sus conciudadanos, y que tal vínculo se exprese mediante instituciones no lucrativas (bibliotecas públicas, organizaciones populares, comunales, escuelas públicas...). Para ser más que consumidores, los ciudadanos deben contar con lugares comunes de encuentro, de reunión y de comunicación (Giroux, 2003, p. 13).

En suma, la cultura popular se está convirtiendo en una respuesta esperanzadora, en la fuerza educativa más importante para la construcción de las percepciones de los 
jóvenes sobre sí mismos y sobre sus relaciones con los otros (2003, p. 77). Esa cultura popular y política se caracteriza por su forma comunitaria, por su carácter dialogal y social. Ese proyecto comunitario puede democratizar el uso de las NTICs, pero para ello debemos cambiar la actitud ante las NTICs provenientes del primer mundo, pues aunque es un hecho que no tenemos la capacidad material para producirlas, podemos reinventar su uso, adaptarlas a nuestras necesidades, intereses y contextos.

\section{Algunos testimonios latinoamericanos sobre la Pedago- gía Crítica ante las NTICs en América Latina.}

Como testimonio de esas prácticas comunitarias en América Latina, están las comunidades eclesiales de base y las comunidades cívicas en el Brasil. Desde allí se ha propiciado un currículum no sólo centrado en la enseñanza (contenido) sino también en el aprendizaje (aprender a aprender), con el fin de evitar la estandarización de la educación a partir de las recetas del FMI y del BM, para toda la América Latina. Pero hay otras experiencias latinoamericanas cercanas a la Pedagogía Crítica con un amplio trabajo popular y emancipador, entre ellas: las radio escuelas de Colombia y las radios mineras de Bolivia ${ }^{71}$.

\section{a) Las Radioescuelas de Colombia}

En Sutatenza, Colombia, un pueblito andino muy alejado, el sacerdote del lugar utilizó astutamente la radio para ofrecer a los campesinos apoyo educativo con el fin de fomentar el desarrollo rural. Para ello creó las "radioescuelas", que eran programas radiales dirigidos a pequeños grupos de vecinos reunidos alrededor de un radio de baterías. Invi-

7 Tomado de BELTRÁN (2005, pp. 3.5). 
taban a líderes comunales acostumbrados a tomar decisiones comunitarias para mejorar la producción, la salud y la educación de la comunidad. Era un proceso de recepción, reflexión, decisión y acción colectivas. Este proyecto fue adoptado por otras comunidades, luego fue apoyado por el gobierno colombiano, y, hasta llegó a tener fama internacional; ayudó a miles de campesinos a mejorar su calidad de vida (produjo también escritos).

Aunque este esfuerzo creativo no fue propiamente un proyecto de la pedagogía crítica, se puede tomar como antecedente transformador dado que coincide con la interpretación crítica y alternativa de las NTICs para alcanzar el mayor objetivo que es la transformación del ser humano y de la sociedad.

\section{b) Las Radios Mineras}

Alrededor de 1950, los sindicatos de trabajadores de las minas de Bolivia se organizaron para crear radioemisoras locales de corto alcance (llamadas por Beltrán (2005, p. 6) como radios Peña), ello a pesar de sus paupérrimos sueldos y sin saber nada, o muy poco, sobre radiofonía, pero dispuestos a comunicarse más efectivamente entre sí y a ser escuchados por otros radio oyentes de cualquier parte del país, tanto en español como en quechua.

Utilizaron el micrófono de forma democrática y gratuita, se les devolvió la palabra a los mineros y a los ciudadanos que quisieran decir algo por el micrófono. Además de la información y la formación sobre reivindicaciones gremiales, se ofrecieron programas educativos, religiosos, agrícolas, y deportivos. Estas radios se extendieron por todo el país, al punto de fundarse las Escuelas Radiofónicas de Bolivia $(E R B O L)^{72}$; lograron una alta conciencia social, un

77 Confronte BELTRAN $(2005$, p. 6). 
mejoramiento de la calidad de vida y, a su vez, se les redujo violentamente por el Estado ante el peligro que representaban para el poder oficial.

Este otro antecedente demuestra que las tecnologías dependen más de la ideología o proyecto político que las impulse, por lo que no se trata de condenarlas o de sacralizarlas, sino de dimensionarlas como herramientas que pueden ser potenciadas para realizar acciones transformadoras dentro de un modelo de desarrollo humanista.

\section{c) Video Alfabetización}

Freire había reconocido el poder potencial de las tecnologías, especialmente el de la TV, como medio de alfabetización, a pesar de considerar esta como un medio aliado al poder dominante (lo cual no ha cambiado actualmente) y de sostener que se le ha usado para alienar pero lo consideraba incapaz de afectar los espíritus críticos (2001, p. 120). Además, señala que el Pedagogo puede recurrir a este medio para utilizarlo como fuente de análisis crítico de los mensajes e imágenes con fines ideológicos allí presentes (ídem, p. 121); es decir, puede servir para alfabetizar críticamente cuando lo usamos dentro de una pedagogía con compromiso político, ético, social y cultural.

Un ejemplo Latinoamericano del uso de la TV, inmenso en una pedagogía que posibilita a los sujetos las condiciones para que se emancipen así mismos, es el de las favelas de Rio de Janeiro en Brasil; allí los sujetos tomaron la palabra, en ellas se aplica un programa de alfabetización crítica mediante la TV local, en el que participa gente de la favela, como educadores o como educandos, y en él se parte de las necesidades, intereses y expectativas de la población, el currículum se contextualiza a la realidad de esas comunidades y la formación política y ética tiende hacia la resistencia, 
emancipación y construcción solidarias de acciones inmediatas. El programa está en su fase inicial (año 2005) y abarca pocas favelas ${ }^{73}$.

Otro programa en las favelas, aunque no es necesariamente de alfabetización crítica, es el de la Radio Bemba. Este proyecto es una especie de Internet local, basado en radio comunicadores de corto alcance, con los que se mantienen intercomunicados en la favela y entre favelas. Se usa con el fin de comunicarse con más constancia, preguntarse cosas, contarse intimidades, relatarse historias cortas de personas de la comunidad, organizar acciones comunitarias, avisar sobre reuniones, hacer cadenas de protesta y resistencia, entre otras tantas acciones más ${ }^{74}$.

Otros programas son las radios comunitarias y alternativas, en las que las comunidades son incentivadas para crear radioemisoras de bajo alcance o alcance local. En estas se estimula la problematización educativa, la acción política y la transformación de la realidad, a partir de acciones concretas que responden a sus necesidades, intereses y expectativas. Entre los países que acogen esta iniciativa y la impulsan por todos sus territorios, tanto citadinos como rurales están Cuba, Venezuela, Uruguay, Bolivia, Ecuador, entre otros. Con ello se pretende darle un contenido de acción y transformación a la democracia formal, actualmente reducida a un formalismo electoral.

\section{Conclusiones}

- El determinismo tecnológico es una tendencia ideológica que legitima el modelo de desarrollo imperante, no es una condición ontológica de las tecnologías.

\footnotetext{
3 Entrevista realizada en julio del 2007 a un habitante de dichas favelas, quien es ducente y educando. La entrevista fue espontánea y realizada mediante lntemet.

74 Entrevista realizada en junio del 2007 , aun participante de Radio Bemba. La entrevista fue espontánea y realizada mediante Internet.
} 
- Las NTICs están políticamente comprometidas, configuran y transmiten ideas y valores ideológicos de quienes las elaboran, que en la actualidad legitiman el modelo de desarrollo vigente en América Latina, propiciador de grandes desigualdades y exclusiones. Pero también puede potenciar un modelo de desarrollo diferente o humanista, si se rediseñan, se recrean y se reconstruyen.

- Para que las tecnologías sean una herramienta al servicio del buen desarrollo, es central el papel de la educación, especialmente ayudada de modelos pedagógicos alternativos; situación urgente para América Latina, pues el uso educativo de las NTICs ha estado desvinculado de un proyecto alternativo de sociedad, de desarrollo y de cultura.

- Esa desvinculación es producto, sobre todo, de la desregulación y desfinanciación del Estado fomentada por el modelo neoliberal, situación que imposibilita aún más la democratización del acceso a dichas tecnologías; al extremo de que América Latina no forma parte de la Sociedad de la Información. Las NTICs estrechan la comunicación entre quienes las utilizan, pero separa a quienes excluye.

- Para democratizar las NTICs y evitar esos desequilibrios sociales y culturales, agravados por el uso desigual, el Estado debe intervenir a través de políticas sociales, culturales y educativas.

- Hoy más que nunca, es necesaria una política educativa que abogue por un modelo de desarrollo humanista, inclusivo, armónico y participativo.

- La Pedagogía Crítica puede ser la herramienta idónea para desarrollar esa nueva política educativa, pues asume a los sujetos como históricos, inacabados y solidarios; por ser una metodología capaz de "concientizar" 
para luchar ante ideologías deshumanizantes y deterministas como el neoliberalismo.

- Por esa razón, es necesaria la "Revitalización de la Cultura de la Política", para formar ciudadanos y no consumidores, seres críticos, reflexivos y sensibles y no autómatas al servicio de las necesidades del mercado.

- La cultura popular es una fuerza educativa esperanzadora, importante para la construcción de un modelo comunitario, dialogal y social (humanista); pues, aunque no tenemos la capacidad material para producir y distribuir las NTICs, podemos reinventar su uso, adaptarlas a nuestras necesidades, intereses y contextos (democratizarlas como ha sucedido en algunos ejemplos citados).

\section{Referencias bibliográficas}

ALVAREZ, G. O. (1999). Integración regional e industrias culturales en el MERCOSUR: situación actual y perspectivas. En Néstor García Canclini y Carlos Moneta (eds). Las industrias Culturales en la Integración Latinoamericana. Buenos Aires: EUDEBA, 165-206.

CARMEN, Raff (2004). Desarrollo Autónomo (Humanización del paisaje: una incursión en el pensamiento y la práctica radical). EUNA, Heredia, Costa Rica.

CASTELL, M. (2003). La Galaxia Internet. Reflexiones sobre Intemet, Empresa y Sociedad. Madrid: Ramón House Mondadori, S.A.

CORDOBA, S. (2005). Centroamérica hacia la sociedad de la información. Manuscrito no publicado.

FREIRE, Pablo (2003). El Grito Manso. Siglo XXI, Argentina.

FREIRE, Pablo (2001). Pedagogía de la Indagación. Morata, Madrid, España. 
FREIRE, Pablo (1980). La Educación como Práctica de la Libertad. Siglo XXI, $27^{\mathrm{a}}$ Edición, México.

GIROUX, H. (2001). Cultura Política y Práctica Educativa. Biblioteca de Aula, España.

GIROUX, H. (1997). Los Profesores como Intelectuales: Hacia una Pedagogía Crítica el Aprendizaje. Paidós, Barcelona, España.

GROS, B. (2000). El ordenador invisible. Hacia la apropiación del ordenador en la enseñanza. Gedisa. Barcelona.

HINKELAMMERT, Franz (1990). Crítica a la Razón Utópica. DEI, Segunda Edición; San José, Costa Rica.

LINUESA, M. Clemente (2004). Lectura y Cultura Escrita. Morata, Madrid, España.

MCLAREN, P. (1997). Pedagogía Crítica y Cultura Depredadora: Políticas de Oposición en la Era Postmoderna. Paidós, Buenos Aries, Argentina.

PÉREZ, Á. (2000). La cultura Escolar en la Sociedad Neoliberal. Morata, Madrid, España.

RIVERO, José (1999). Educación y Exclusión en América Latina: Reformas en Tiempos de Globalización. MD Editores, Madrid, España.

YUDICE, J. (2001). La Reconfiguración de las políticas culturales y mercados culturales en los 1990s y siglo XXI en América Latina. New York: NYU. Manuscrito del autor (Publicado en Revista Iberoamericana).

YUDICE, J. (1999). La industria de la Música en la integración América Latina-Estados Unidos. En Néstor García Canclini y Carlos Moneta (eds). Las industrias Culturales en la Integración Latinoamericana, Buenos Aires: EUDEBA, 125-134.

\section{Webgrafía}

AREA, M. (2002). Problemas y retos educativos ante las tecnologías digitales en la sociedad de la información. En Revista Quaderns Digitals, no. 28. http://www.quadernsdigitals.net. http://webpages.ull.es/users/manarea/Documentol5.html. 
AREA, Manuel (1998). Nuevas tecnologías, desigualdad y educación en las sociedades de la información. Universidad de la Laguna, España. En http://www.ìeev.uma.es/edutec97_c4/ 2-4-14.html.

BELTRÁN, Luis Ramiro (2005). La comunicación para el desarrollo en Latinoamérica: un recuento de medio siglo. En III Congreso Panamericano de la Comunicación, Universidad de Buenos Aires, Julio 12-16, 2005, Buenos Aires http:// www.audiovisualcat.net/publicaciones/Q21 cas.html).

KAPLÚN, Gabriel (2004). Culturas juveniles y educación: pedagogía crítica, estudios culturales e investigación participativa (La cumbia villera y concheta, el rock de la calle y la escuela). En http:// www.liccom.edu.uy/interes/actividades/2005/ archivos/Ciencia_de_la_Comunicacion (Liceos_y_UTU).pdf

TEDESCO, Alicia Beatriz (1997). Educación a distancia y Nuevas Tecnologías: La Formación de docentes críticos. En http:/ /www.rieoei.org/deloslectores/653tedesco.PDF 